\title{
Seasonal Modulation of Eddy Kinetic Energy and Its Formation Mechanism in the Southeast Indian Ocean
}

\author{
FAN JIA AND LIXIN WU \\ Physical Oceanography Laboratory, Ocean University of China, Qingdao, China \\ Bo QIU \\ Department of Oceanography, University of Hawaii at Manoa, Honolulu, Hawaii
}

(Manuscript received 21 January 2010, in final form 17 November 2010)

\begin{abstract}
Mesoscale eddy activity in the southeast Indian Ocean $\left(15^{\circ}-30^{\circ} \mathrm{S}, 60^{\circ}-110^{\circ} \mathrm{E}\right)$ is investigated based on available satellite altimetry observations. The observed sea level anomaly data show that this region is the only eastern basin among the global oceans where strong eddy activity exists. Furthermore, the eddy kinetic energy (EKE) level in this region displays a distinct seasonal cycle with the maximum in austral summer and minimum in austral winter. It is found that this seasonal modulation of EKE is mediated by baroclinic instability associated with the surface-intensified South Indian Countercurrent (SICC) and the underlying South Equatorial Current (SEC) system. In austral spring and summer the enhanced flux forcing of combined meridional Ekman and geostrophic convergence strengthens the upper-ocean meridional temperature gradient, intensifying the SICC front and its vertical velocity shear. Modulation of the vertical velocity shear results in the seasonal changes in the strength of baroclinic instability, leading to the seasonal EKE variations in the southeast Indian Ocean.
\end{abstract}

\section{Introduction}

Ocean mesoscale eddies account for a major portion of the ocean kinetic energy and exert profound impacts on large-scale ocean circulations. Satellite altimeter observations have been providing a unique opportunity to examine the mesoscale oceanic processes and their associations with the large-scale oceanic circulations and the climate.

The global eddy kinetic energy (EKE) distribution calculated from the sea level anomaly (SLA) data demonstrates high EKE bands located in the western part of the global ocean basins and along the Antarctic Circumpolar Current (ACC) (Fig. 1). Most of the studies so far have focused on the EKE variations in the western boundary current extension and ACC regions (e.g., Ebuchi and Hanawa 2000; Imawaki et al. 2001; Qiu 2002; Phillips and Rintoul 2000; Ladd 2007) where mesoscale eddies

Corresponding author address: Lixin Wu, Physical Oceanography Laboratory, Ocean University of China, 238 Songling Road, Qingdao 266100, China.

E-mail: 1xwu@ouc.edu.cn are associated strongly with the basin-scale climatic fluctuations: for example, the Pacific decadal oscillation (PDO), the North Atlantic Oscillation (NAO), and the southern annular mode (SAM) (e.g., Miller and Schneider 2000; De Weaver and Nigam 2000; Biondi et al. 2001; Penduff et al. 2004; Screen et al. 2009; Sen Gupta and England 2007). Recent studies also examined mesoscale eddy activities in the North Pacific Subtropical Countercurrent and the South Pacific regions (e.g., Qiu 1999; Kobashi and Kawamura 2002; Qiu and Chen 2004, 2010). These studies suggested that the seasonal variations of EKE in these regions are predominantly regulated by baroclinic instability associated with the background mean flows.

Mesoscale eddy activities have also been studied in the eastern Indian Ocean associated with the South Equatorial Current (SEC) (e.g., Palastanga et al. 2007; Zhou et al. 2008). In the subtropical Indian Ocean, a high EKE band can be found around $25^{\circ} \mathrm{S}$ extending westward from the Australian coast (Fig. 1). It is the only high EKE band occurring near the subtropical eastern boundary of the global oceans. This band corresponds to where the shallow, eastward-flowing South Indian Ocean Countercurrent (SICC) is located and has 


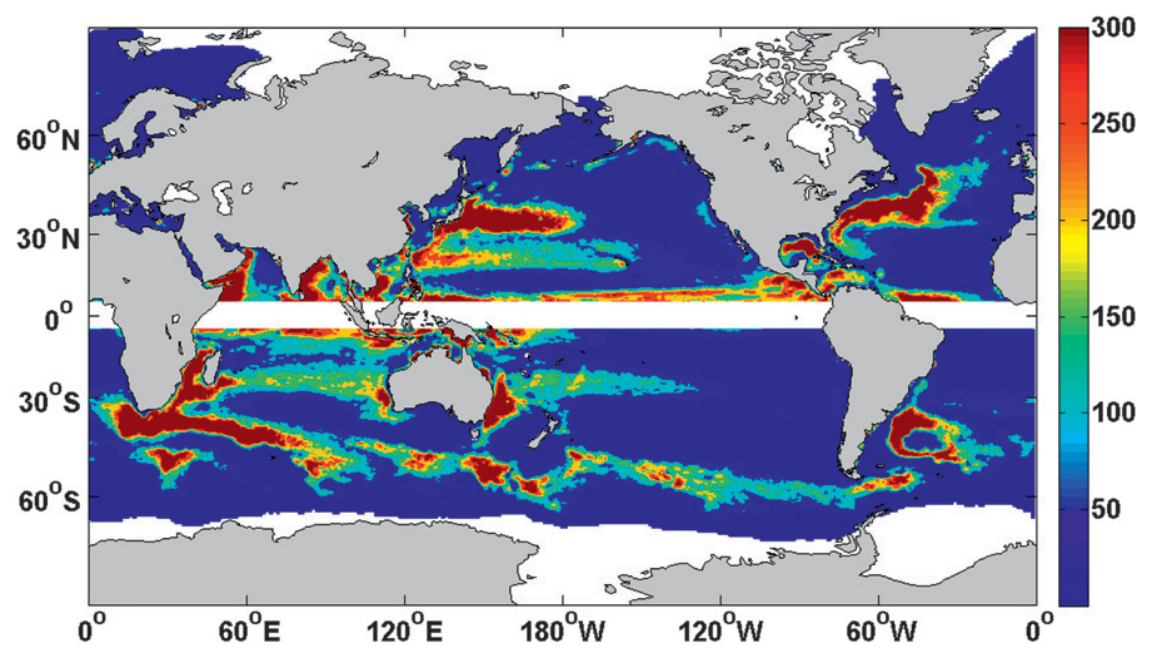

FIG. 1. Global EKE $\left(\mathrm{cm}^{2} \mathrm{~s}^{-2}\right)$ calculated from the 15-yr SLA data after applying a 300-day high-pass filter.

a structure similar to the subtropical countercurrents (STCCs) in the North and South Pacific Oceans (Palastanga et al. 2007; Siedler et al. 2006). Using a twolayer model, Palastanga et al. (2007) showed that regions of large vertical shear along the SICC-SEC system are baroclinically unstable. The frequencies (3.5-6 times per year) and wavelengths $(290-470 \mathrm{~km})$ of the unstable modes are shown to be close to the observed values derived from the satellite altimetry data. They also mentioned that the EKE along $25^{\circ} \mathrm{S}$ exhibited a regular seasonal variation with a maximum in November and a minimum in May.

The baroclinic instability associated with the currents in the tropical region has been documented in other studies (e.g., Feng and Wijffels 2002; Zhou et al. 2008). Feng and Wijffels demonstrated that strong intraseasonal signals could be found along $12^{\circ} \mathrm{S}$ during the second half of a year. The signal has a wavelength of 400-600 km with a westward phase speed of $15-19 \mathrm{~cm} \mathrm{~s}^{-1}$ and a dominant period between 40 and 80 days. Zhou et al. analyzed model simulations in the Indo-Pacific region and also found that the intraseasonal oscillations have a period of $40-80$ days with a wavelength of $\sim 650 \mathrm{~km}$. These studies suggested an important role of baroclinic instability in driving the observed intraseasonal variations.

The current study extends the earlier work of Palastanga et al. (2007) to explain the mechanism of the seasonal variations of the eddy activity in the southeast Indian Ocean based on the observational data and baroclinic instability theoretical analyses. The paper is outlined as follows: In section 2, we start with a brief description of the data used here. The seasonal cycle of EKE in the southeast Indian Ocean is presented in the next section. Section 4 discusses the mechanism underlying the observed seasonal EKE cycle, and section 5 explores the forcing that modulates the seasonal changes in the background SICC. The paper is concluded with a summary and discussions in section 6 .

\section{Data}

The data used in this study, including temperature and salinity are from the World Ocean Atlas 2009 (WOA09), which is a set of objectively analyzed $\left(1^{\circ}\right.$ grid $)$ climatological fields of in situ data for the World Ocean (Locarnini et al. 2010; Antonov et al. 2010). The wind stress and surface heat flux data used in the paper are from the National Centers for Environmental PredictionNational Center for Atmospheric Research reanalysis product (Kalnay et al. 1996). We also use the satellite altimetry "Ref" (M) SLA delayed time products produced by Segment Sol Multimissions d'Alimétrie, d'Orbitographie et de Localization Precise/Data Unification and Altimeter Combination System (Ssalto/Duacs) and distributed by Archiving, Validation, and Interpretation of Satellite Oceanographic data (AVISO) with support from the Centre National d'Études Spatiales (CNES; available online at http://www.aviso.oceanobs.com/en/data/products/ sea-surface-height-products/global/msla/index.html), which contain the multimission [from October 1992 to August 2002: Ocean Topography Experiment (TOPEX)/ Poseidon + European Remote Sensing Satellite-1 (ERS-1) or ERS-2; from August 2002 to June 2003: Jason-1 + ERS-2; from June 2003 to January 2008: Jason-1 + Envisat] gridded sea surface heights computed with respect to a 7 -yr mean. The dataset has a weekly format on a $1 / 3^{\circ} \times 1 / 3^{\circ}$ Mercator grid and covers the period from October 1992 to January 2008. 

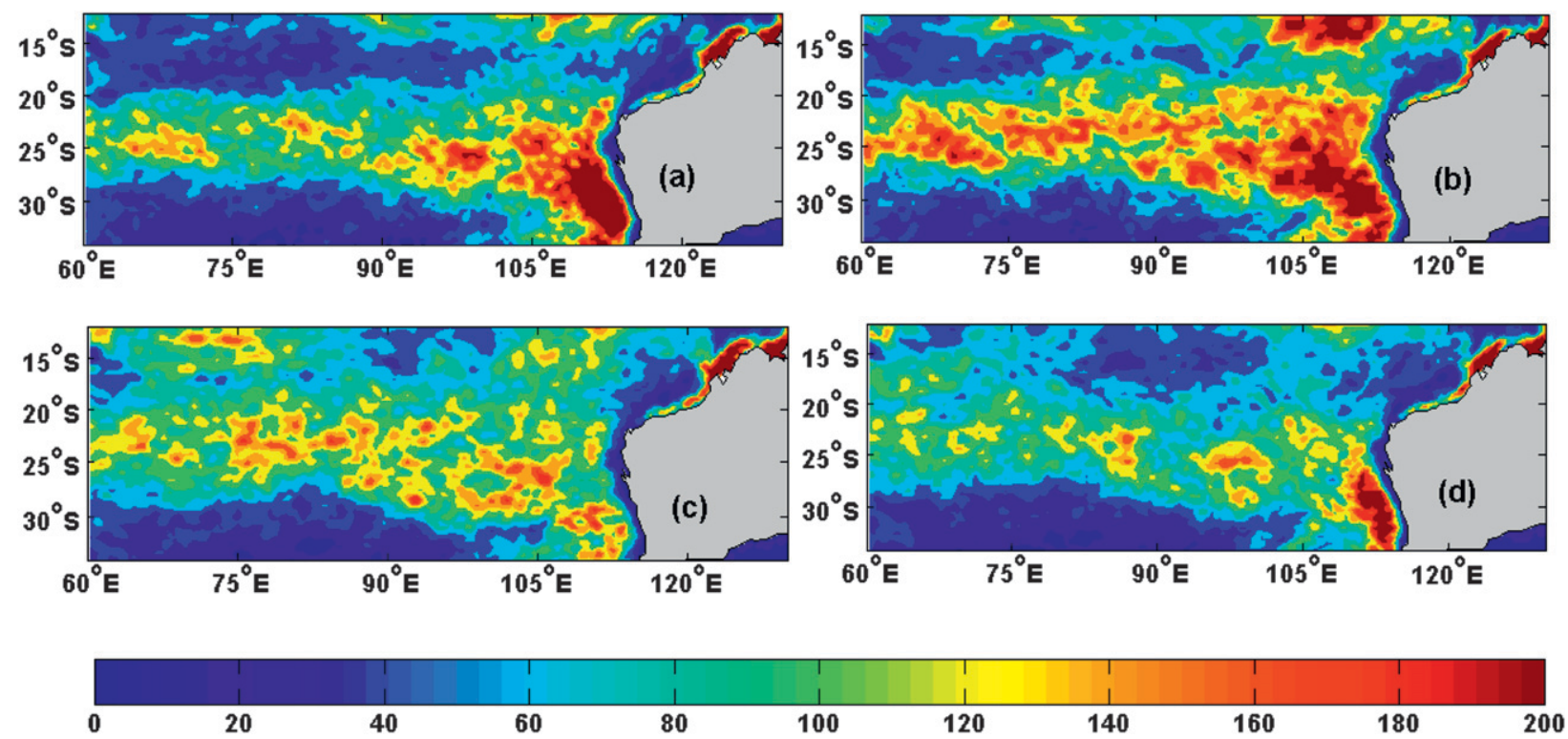

FIG. 2. Seasonal distributions of EKE in the southeast Indian Ocean in (a) spring [August-October (ASO)], (b) summer (NDJ), (c) autumn [February-April (FMA)], and (d) winter (MJJ).

\section{Seasonal cycle of EKE in the southeast Indian Ocean}

The EKE value is estimated based on geostrophic calculation as follows:

$$
\begin{aligned}
\mathrm{EKE} & =\frac{1}{2}\left(U_{g}^{\prime 2}+V_{g}^{\prime 2}\right), \\
U_{g}^{\prime} & =-\frac{g}{f} \frac{\Delta \eta^{\prime}}{\Delta y}, \quad \text { and } \quad V_{g}^{\prime}=\frac{g}{f} \frac{\Delta \eta^{\prime}}{\Delta x},
\end{aligned}
$$

where $U_{g}^{\prime}$ and $V_{g}^{\prime}$ are the geostrophic velocities, $f$ is the Coriolis parameter, and $\eta^{\prime}$ is the SLA. To emphasize the contribution from the mesoscale eddy signals, the EKE value in this study is calculated based on the 300-day high-pass filtered $\eta^{\prime}$ data.

The EKE maps in the southeast Indian Ocean in four different seasons are constructed from the 15-yr SLA data (January 1993-December 2007). As shown in Fig. 2, EKE displays a distinct seasonal cycle with a maximum in austral summer [November-January (NDJ)] and its minimum in austral winter [May-July (MJJ)] (hereafter all seasons will be referred to as austral seasons unless otherwise specified). This seasonal cycle is similar to the seasonal changes of EKE along $25^{\circ} \mathrm{S}$ noted by Palastanga et al. (2007). To further demonstrate the seasonal dependence, we calculate the time series of EKE averaged in the region $15^{\circ}-30^{\circ} \mathrm{S}, 60^{\circ}-110^{\circ} \mathrm{E}$ (Fig. 3a) and its mean seasonal cycle (Fig. 3b). Seasonal variations can be clearly identified, with a mean EKE of $96.4 \mathrm{~cm}^{2} \mathrm{~s}^{-2}$, a maximum of $115 \mathrm{~cm}^{2} \mathrm{~s}^{-2}$ in December, and a minimum of $\sim 80 \mathrm{~cm}^{2} \mathrm{~s}^{-2}$ in May (Fig. 3b). The peak-to-peak EKE difference is about $40 \%$ of the regionalmean EKE level.

It is worth noting that EKE in the southeast Indian Ocean also displays significant interannual and decadal variability (Fig. 3a). For instance, the EKE level is higher in 1995-97 and 1999-2003 and lower in 1993-94, 1997-99, and 2004-06. Previously, Feng et al. (2003) studied the ENSO-related interannual variations of the Leeuwin Current at $32^{\circ} \mathrm{S}$ in this region and found that the Leeuwin Current was distinctly stronger during a La Niña year and weaker during an El Niño year. In this paper, we will focus mainly on the seasonal EKE signals.

\section{Formation mechanism of the seasonal cycle}

Seasonal modulations of mesoscale eddy activities in the subtropical Pacific and Atlantic Oceans have been attributed to baroclinic instability of the background mean circulation (e.g., Halliwell et al. 1994; Qiu 1999; Qiu and Chen 2004). Here, we first examine seasonal variations of the thermal structure in the southeast Indian Ocean using the WOA09 data.

The isotherms in the upper $150-\mathrm{m}$ of the southeast Indian Ocean display a distinct seasonal variation (Fig. 4). South of $15^{\circ} \mathrm{S}$ the outcropping lines of the isotherms progressively migrate toward the high latitudes from winter/spring (Figs. 4d,a) to summer/autumn (Figs. 4b,c). Associated with the poleward migration of these outcropping lines, the isotherms also become shallow and flat. In contrast, the isotherms below $150 \mathrm{~m}$ (roughly the 

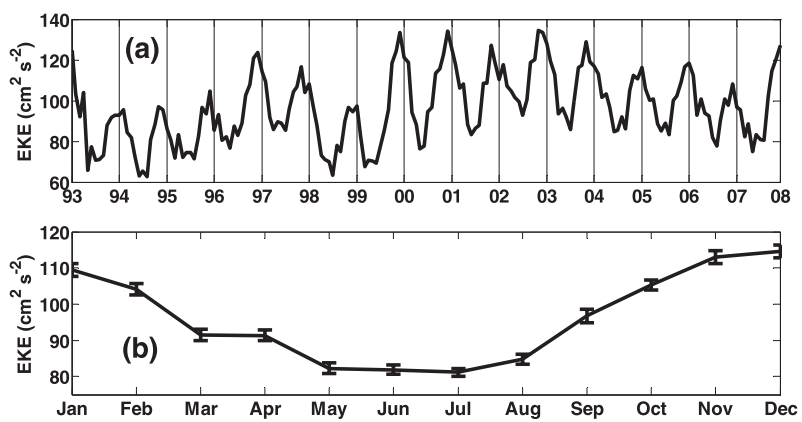

FIG. 3. (a) Time series of EKE averaged in the southeast Indian Ocean $\left(15^{\circ}-30^{\circ} \mathrm{S}, 60^{\circ}-110^{\circ} \mathrm{E}\right)$, (b) Mean seasonal cycle of EKE constructed from (a); standard deviation bars are also shown.

mixed layer depth) remain stable and correspond to the permanent thermocline.

The seasonal variation in the sloping of the surface isotherms leads to a change in the upper-ocean baroclinicity in different seasons. To demonstrate that, we calculate the zonal geostrophic velocity based on the WOA09 temperature and salinity profile with the level of no motion at $2000 \mathrm{~m}$. Figure 5 displays the zonal velocity along $85^{\circ} \mathrm{E}$ in the southeast Indian Ocean. The core of the SEC is located between $5^{\circ}$ and $15^{\circ} \mathrm{S}$ and extends southward to about $20^{\circ} \mathrm{S}$ at $500-\mathrm{m}$ depth. The SEC also displays a distinct seasonal variation with a strongest magnitude in summer (Fig. 5b). Relative to the SEC, the eastward-flowing SICC is a much weaker and shallower flow with its core located within $20^{\circ}-30^{\circ} \mathrm{S}$ and trapped in the upper $200 \mathrm{~m}$. One distinct feature of the SICC is its equatorward extension in the summer (Fig. $5 b)$ due to the poleward tilt of the seasonal thermocline (Fig. 4b). As a result, the vertical shear is intensified. Changes in the vertical shear with seasons between $15^{\circ}$ and $30^{\circ} \mathrm{S}$ are further demonstrated in Fig. 6, showing the vertical profile of the domain-averaged zonal velocity. The eastward flow in the upper $150 \mathrm{~m}$ attains a maximum of $\sim 3.3 \mathrm{~cm} \mathrm{~s}^{-1}$ in summer and a minimum of $\sim 2.4 \mathrm{~cm} \mathrm{~s}^{-1}$ in winter, while the westward flow in the lower layer changes less significantly. Here, we define the vertical shear as the difference of the mean eastward flow velocity in the upper layers and westward flow velocity in the lower layers. So, the vertical velocity shear peaks in spring/summer and decreases in autumn/winter. It should be noted that, if we define the vertical shear as the difference of the maximum westward and eastward velocity in the upper and lower layers, it will not change our conclusions in this paper.

To clarify how the seasonal variation of EKE relates to the vertical shear, the monthly vertical shear and the EKE are plotted in Fig. 7a. The vertical shear has a maximum of $3.7 \mathrm{~cm} \mathrm{~s}^{-1}$ in August-September and a minimum of $2.6 \mathrm{~cm} \mathrm{~s}^{-1}$ in March, while the EKE reaches
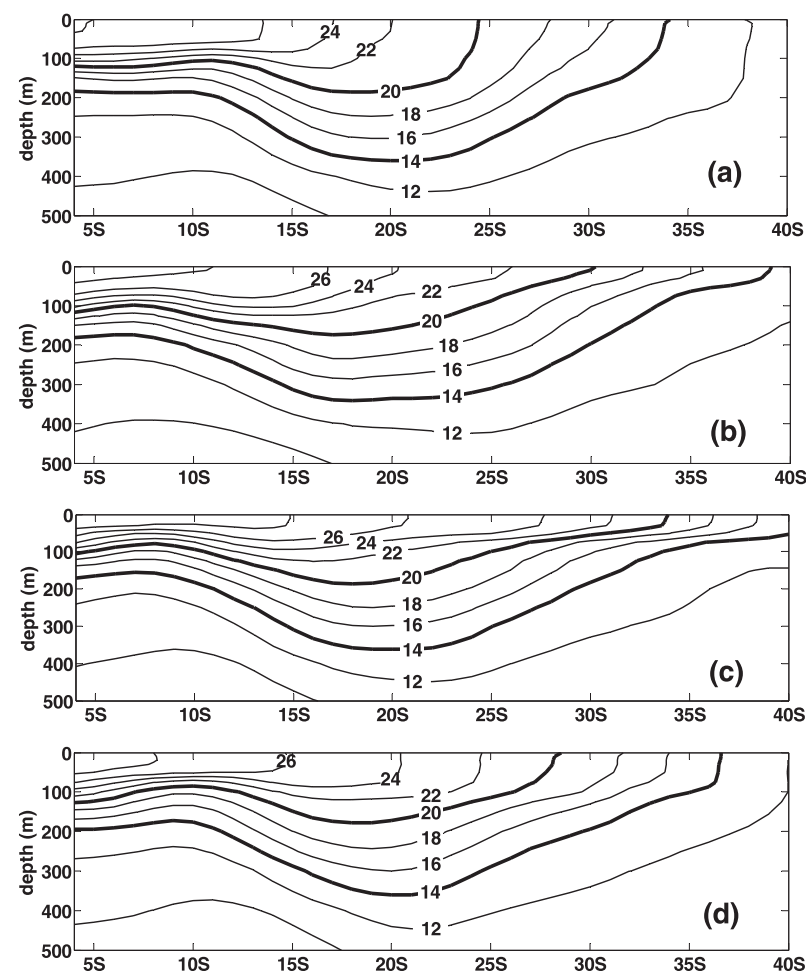

FIG. 4. Latitude-depth profile of temperature $\left({ }^{\circ} \mathrm{C}\right)$ (solid contours) along $85^{\circ} \mathrm{E}$ in the southeast Indian Ocean in different months: (a) September, (b) December, (c) March, and (d) June.

a maximum in November-December and a minimum in May-July. This indicates that the vertical shear precedes the EKE variation by about $2 \sim 4$ months. To further demonstrate the phase relationship between the EKE and vertical shear at seasonal time scale, the vertical shear time series is shifted by two months to align with the EKE at its maximum phase (December) (Fig. 7b). It can be seen that the vertical shear leads the EKE further by about two months at its minimum phase (July), suggesting a varying phase relationship between the EKE and vertical shear. A similar correlation between the vertical velocity shear and the EKE is also found in the North Equatorial Current (NEC) and STCC region of the North Pacific (Qiu 1999). In the following, we examine how seasonally varying velocity shear between the SICC and the underlying SEC affects the EKE in the southeast Indian Ocean.

Following Qiu (1999), we adopt a 21/2-layer reducedgravity model with two active upper layers and an infinitely deep abyssal layer to simplify the southeast Indian Ocean. The governing quasigeostrophic equation for the active two upper layers can be expressed by

$$
\left(\frac{\partial}{\partial t}+U_{n} \frac{\partial}{\partial x}\right) q_{n}+\frac{\partial \Pi_{n}}{\partial y} \frac{\partial \varphi_{n}}{\partial x}=0,
$$



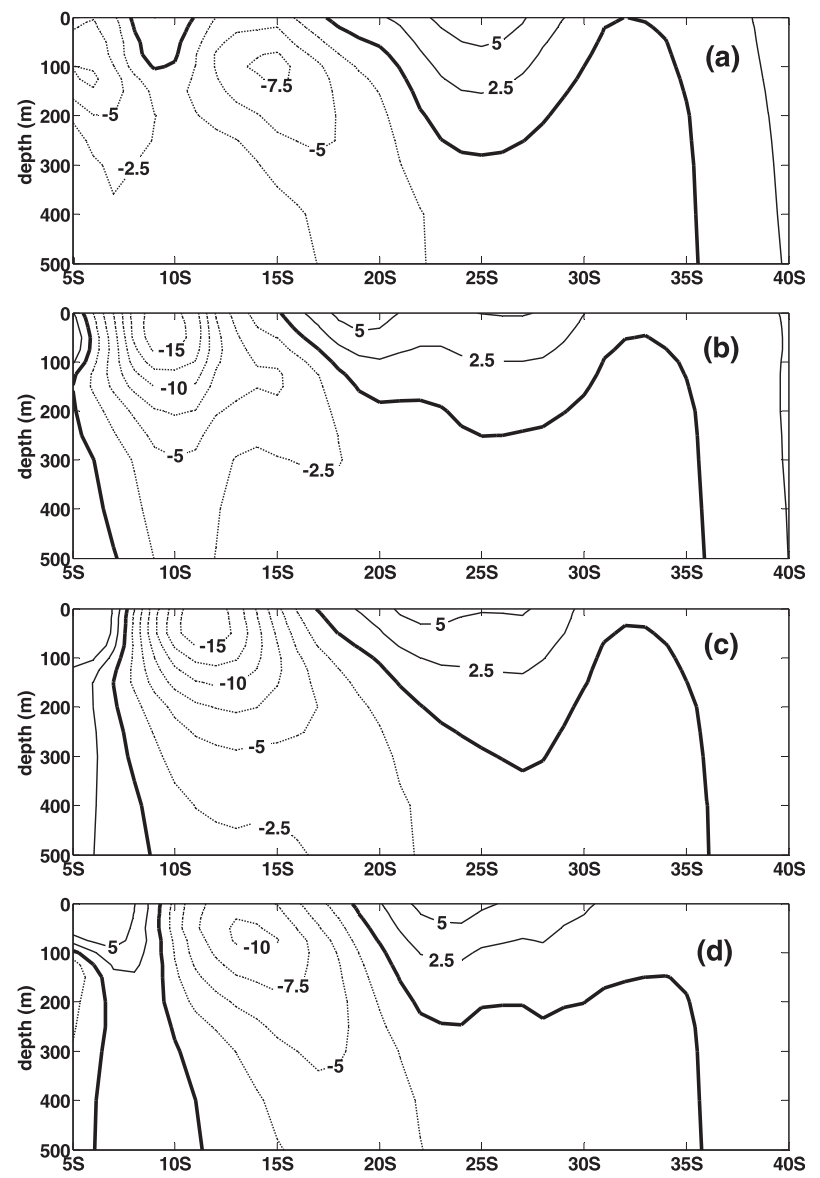

FIG. 5. As in Fig. 4 but for the zonal velocity, Contour interval $2.5 \mathrm{~cm} \mathrm{~s}^{-1}$. This is based on the WOA09 T-S profiles with the level of no motion at 2000-m. Solid (dashed) contours indicate eastward (westward) flow.

where $U_{n}$ is the zonal geostrophic velocity, $q_{n}$ is the perturbation potential vorticity, $\varphi_{n}$ is the perturbation streamfunction, and $\Pi_{n}$ is the mean potential vorticity in the $n$th layer $(n=1$ and 2$)$.

To focus on baroclinic instability, we assume in this study that the mean flow $U_{n}$ is meridionally uniform. Then $q_{n}$ and $\Pi_{n}$ can be expressed by

$$
\begin{aligned}
q_{1} & =\nabla^{2} \phi_{1}+\frac{1}{\gamma \delta \lambda^{2}}\left(\phi_{2}-\phi_{1}\right), \\
q_{2} & =\nabla^{2} \phi_{2}+\frac{1}{\gamma \lambda^{2}}\left(\phi_{1}-\phi_{2}-\gamma \phi_{2}\right), \\
\Pi_{1 y} & =\beta+\frac{1}{\gamma \delta \lambda^{2}}\left(U_{1}-U_{2}\right),
\end{aligned}
$$

and

$$
\Pi_{2 y}=\beta-\frac{1}{\gamma \lambda^{2}}\left(U_{1}-U_{2}-\gamma U_{2}\right)
$$

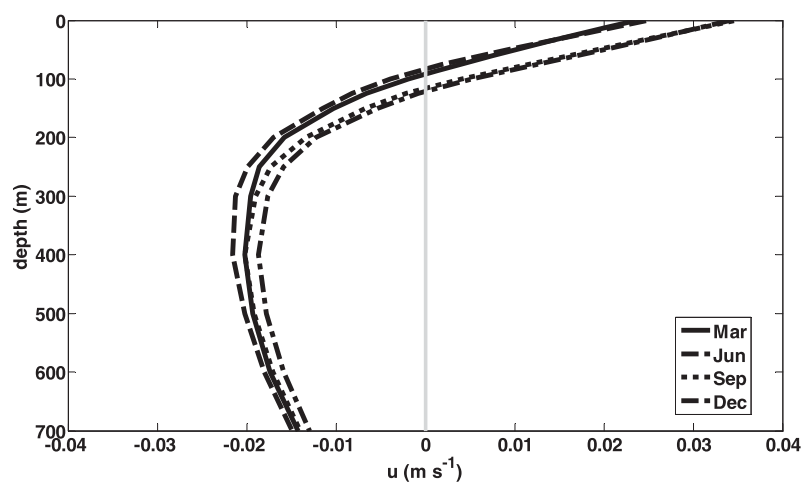

FIG. 6. Vertical profile of zonal velocity averaged over the region $15^{\circ}-30^{\circ} \mathrm{S}, 60^{\circ}-110^{\circ} \mathrm{E}$.

in which $\delta \equiv H_{1} / H_{2}, \gamma \equiv\left(\rho_{2}-\rho_{1}\right) /\left(\rho_{3}-\rho_{2}\right)$ is the stratification ratio,

$$
\lambda \equiv \frac{1}{f_{0}} \sqrt{\frac{\left(\rho_{3}-\rho_{2}\right)}{\rho_{0}} g H_{2}}
$$

is the internal Rossby radius, $\beta=\left(2 \Omega \cos \phi_{0}\right) / R$, and $f_{0}$ is the Coriolis parameter at the reference latitude $25^{\circ} \mathrm{S}$.

Assume that Eq. (2) has a normal mode solution; then

$$
\phi_{n}=A_{n} \cos (k x+l y-k c t) .
$$

An instability criterion as well as a dispersion relationship can be obtained as follows:

$$
U_{1}-U_{2}-\gamma U_{2}>\gamma \lambda^{2} \beta
$$

and

$$
\begin{aligned}
& c^{2}-\left(U_{1}+U_{2}-\frac{P+Q}{R}\right) \\
& c+\left(U_{1} U_{2}+\frac{\Pi_{1 y} \Pi_{2 y}}{R}-\frac{U_{1} P}{R}-\frac{U_{2} Q}{R}\right)=0,
\end{aligned}
$$

where $P, Q$, and $R$ are functions of $k, l, \delta$ and $\lambda$ (for details, see Qiu 1999). The instability criterion implies that, once the condition (8) is satisfied, the system becomes unstable. Notice that a stronger vertical velocity shear, $U_{1}-U_{2}$, and a weaker stratification $\gamma$ can lead to enhanced baroclinic instability. Equation (9) is the dispersion relationship for wave speed $c\left(c=c_{r}+i c_{i}\right)$ from which we may detect the growth rate $\left(k c_{i}\right)$ of the SICCSEC system and compare with the observed results.

With parameters appropriate for the southeast Indian Ocean (Table 1), the dispersion relationship, Eq. (9), is 

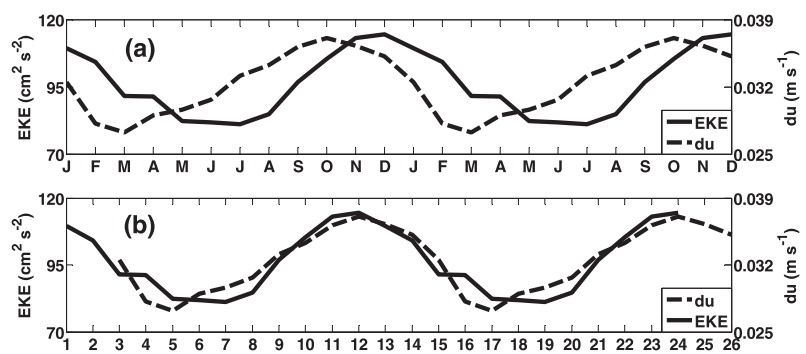

FIG. 7. (a) Monthly vertical velocity shear (dashed line) and EKE (solid line) averaged in the southeast Indian Ocean and (b) the vertical shear time series (dashed line) aligned with the EKE (solid line) at its maximum phase (December) by shifting two months.

solved and the growth rates for the unstable waves are displayed in Fig. 8. We choose September-October and March-April since they represent the strongest versus weakest months of the SICC-SEC shear according to Fig. 7a. It is clear that the system is unstable under both September-October and March-April conditions $\left(c_{i} \neq\right.$ $0)$, and the preferred wavelength scale of the most unstable waves is $\sim 200 \mathrm{~km}$ (Fig. 8), but there are also many differences. The most unstable wave in SeptemberOctober has $k c_{i}=0.016$ day $^{-1}$, or an $e$-folding time scale of 60 days (Fig. 8a), whereas the most unstable wave in March-April is 0.008 day $^{-1}$ or an $e$-folding time scale of 125 days (Fig. 8b). In addition, the window for permissible unstable waves in September-October is broader than that in March-April (cf. Fig. 8a versus 8b). Therefore, the system in September-October is baroclinically more unstable than that in March-April. Notice the major differences between the two are the parameters $U_{1}-U_{2}$ and $\gamma$. In September-October $U_{1}-U_{2}$ is $0.036 \mathrm{~m} \mathrm{~s}^{-1}$ and in March-April it decreases to $0.026 \mathrm{~m} \mathrm{~s}^{-1}$. The stratification ratio $\gamma$ is 1.75 in September-October and increases to 2.39 in MarchApril. Both the weaker stratification and stronger vertical velocity shear in September-October work to intensify baroclinic instability and result in enhanced mesoscale eddy activities after the $e$-folding time scale of the unstable waves.

To compare with the observed mesoscale eddy propagation speed and wavelength scale, we show in Fig. 9 the time-longitude plot of high-pass filtered SLA along $25^{\circ} \mathrm{S}$. The dominant eddy time scale is $\sim 90$ days and the wavelength scale $\sim 200 \mathrm{~km}$. The wavelength scale corresponds well with the most unstable wave characteristics obtained from the instability analysis above (Fig. 8).

In summary, the $2 \frac{1}{2}-$-layer reduced-gravity model results support the argument that the seasonal variation in intensity of the baroclinic instability of the SICC-SEC current system modulates the eddy kinetic energy in the southeast Indian Ocean.
TABLE 1. Parameter values of the region in September-October and March-April. The reference latitude for $f_{0}$ and $\beta$ is at $25^{\circ} \mathrm{S}$; the other parameter values are estimated from the SODA data.

\begin{tabular}{ccc}
\hline Parameter & Sep-Oct & Mar-Apr \\
\hline$f_{0}$ & $-6.16 \times 10^{-5} \mathrm{~s}^{-1}$ & $-6.16 \times 10^{-5} \mathrm{~s}^{-1}$ \\
$\beta$ & $2.07 \times 10^{-11} \mathrm{~s}^{-1} \mathrm{~m}^{-1}$ & $2.07 \times 10^{-11} \mathrm{~s}^{-1} \mathrm{~m}^{-1}$ \\
$U_{1}$ & $0.021 \mathrm{~m} \mathrm{~s}^{-1}$ & $0.011 \mathrm{~m} \mathrm{~s}^{-1}$ \\
$U_{2}$ & $-0.015 \mathrm{~m} \mathrm{~s}^{-1}$ & $-0.015 \mathrm{~m} \mathrm{~s}^{-1}$ \\
$H_{1}$ & $150 \mathrm{~m}$ & $150 \mathrm{~m}$ \\
$H_{2}$ & $300 \mathrm{~m}$ & $300 \mathrm{~m}$ \\
$\rho_{1}$ & $24.80 \sigma_{\theta}$ & $24.10 \sigma_{\theta}$ \\
$\rho_{2}$ & $26.71 \sigma_{\theta}$ & $26.71 \sigma_{\theta}$ \\
$\rho_{3}$ & $27.80 \sigma_{\theta}$ & $27.80 \sigma_{\theta}$ \\
$\gamma$ & 1.75 & 2.39 \\
\hline
\end{tabular}

\section{Origin of seasonal variations of vertical velocity shear}

The above analysis points to the important role of the vertical velocity shear in modulating the seasonal variations of the eddy kinetic energy. In this section, we explore the physical processes that are important to the seasonal evolution of the vertical velocity shear in the southeast Indian Ocean. Notice that the density calculated from WOA09 temperature and salinity data in this region behaves quite similarly to the temperature (figure not shown here), indicating that the salinity effect is of secondary importance. Through the thermal wind balance in this case, we have

$$
f \frac{\partial U_{g}}{\partial z}=-\alpha g \frac{\partial T}{\partial y}
$$

where $f$ is the Coriolis parameter and $\alpha$ is the thermal expansion coefficient. The vertical velocity shear's seasonal variations are thus related to the seasonal variations in the upper ocean's meridional temperature gradient.

We define $G \equiv \partial T / \partial y$, where a positive $G$ indicates an enhanced isotherm slope and thus vertical shear (recall $f$ is negative in the southeast Indian Ocean). From the governing equation for temperature, we have

$$
\begin{aligned}
\frac{\partial G}{\partial t}= & \frac{\partial}{\partial y}\left(\frac{\partial T}{\partial t}\right)=\frac{\partial}{\partial y}\left(-v \frac{\partial T}{\partial y}-w \frac{\partial T}{\partial z}+\frac{Q_{\text {net }}}{\rho_{o} C_{p} H_{1}}+\text { diff }\right) \\
= & -\frac{\partial}{\partial y}\left[\left(v_{g}+v_{\mathrm{Ek}}\right) G\right]-\frac{\partial}{\partial z}(w G)+\frac{\partial}{\partial y}\left(\frac{Q_{\text {net }}}{\rho_{o} C_{p} H_{1}}\right) \\
& +\frac{\partial}{\partial y}(\text { diff }),
\end{aligned}
$$

where $v_{\mathrm{Ek}}=-\tau^{x} / \rho_{0} f H_{0}$ is the meridional Ekman velocity averaged in the surface layer, $\tau^{x}$ is the zonal wind stress, $\rho_{0}$ is the reference density, $Q_{\text {net }}$ is the net surface 

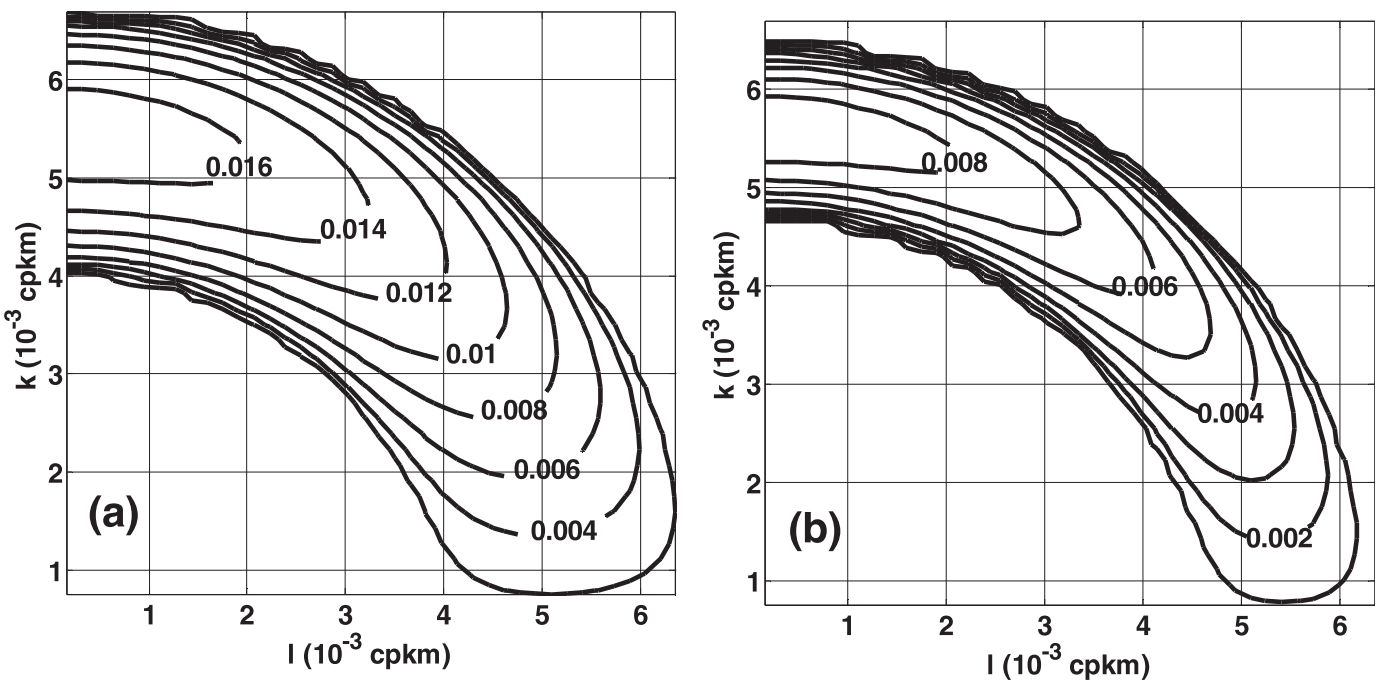

FIG. 8. Growth rate $\left(\mathrm{day}^{-1}\right)$ of the unstable waves as a function of zonal and meridional wavenumber in (a) September-October and (b) March-April.

heat flux, $C_{p}$ is the specific heat of ocean water, diff is the diffusion terms, $u_{g}$ and $v_{g}$ are the zonal and meridional geostrophic velocity, $u_{\mathrm{Ek}}$ and $v_{\mathrm{Ek}}$ are the zonal and meridional Ekman velocity, respectively, and $H_{1}$ the thickness of the surface layer. Here $H_{1}$ is set to $150 \mathrm{~m}$ in agreement with the $2 \frac{1}{2} 2$-layer system. In Eq. (11), we have neglected the zonal temperature gradient advection term because our interest is in the zonally averaged $G$ values.

By evaluating the five terms on the rhs of Eq. (11) with the use of the Simple Ocean Data Assimilation (SODA 2.0.2-4) product, we confirmed that

$$
-\frac{\partial}{\partial z}(w G)+\frac{\partial}{\partial y}(\text { diff })
$$

is unimportant (figure not shown here). With this, Eq. (11) may be simplified to

$$
\frac{\partial G}{\partial t} \approx-\frac{\partial}{\partial y}\left(v_{\mathrm{Ek}} G\right)-\frac{\partial}{\partial y}\left(v_{g} G\right)+\frac{\partial}{\partial y}\left(\frac{Q_{\mathrm{net}}}{\rho_{o} C_{p} H_{1}}\right) .
$$

Physically, it indicates that changes in $G$ are largely controlled by the sum of the meridional Ekman flux convergence, the meridional geostrophic flux convergence, and the convergence of the latitudinally dependent surface heat flux forcing. Seasonal variations in these three convergence terms are shown in Fig. 10a. The Ekman flux convergence forcing peaks in July-September and decreases to a minimum in March, lagging the seasonal development of the Indian monsoon by about one month. This represents the time required for the upper ocean to adjust to the seasonally varying wind stresses. The meridional geostrophic convergence forcing shows variations similar to the surface Ekman flux convergence forcing.
The surface heat flux forcing, on the other hand, has a seasonal variation out of phase with those of the meridional flux convergence forcings. The sum of these three forcings corresponds quite well with the seasonal changes in the vertical velocity shear with leads of about one to two months, representing the time scale of the upper-ocean adjustment (Fig. 10b). The dynamic forcings are therefore more important than the thermodynamic forcing in modulating the seasonal variations of the velocity vertical shear.

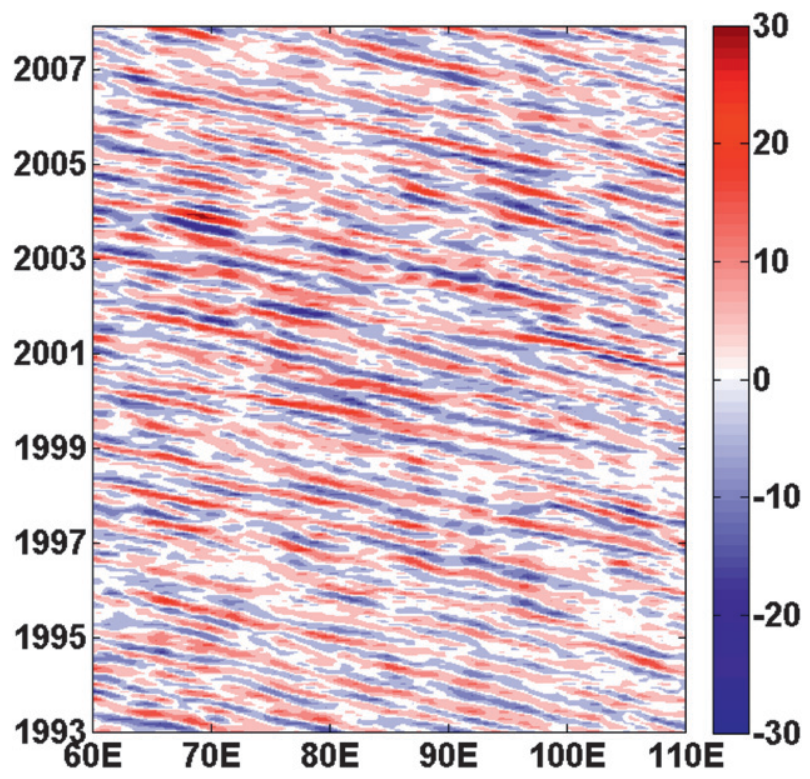

FIG. 9. Time-longitude plot of 300-day high-pass filtered SLA along $25^{\circ} \mathrm{S}$ in the southeast Indian Ocean from January 1993 to December 2007. 

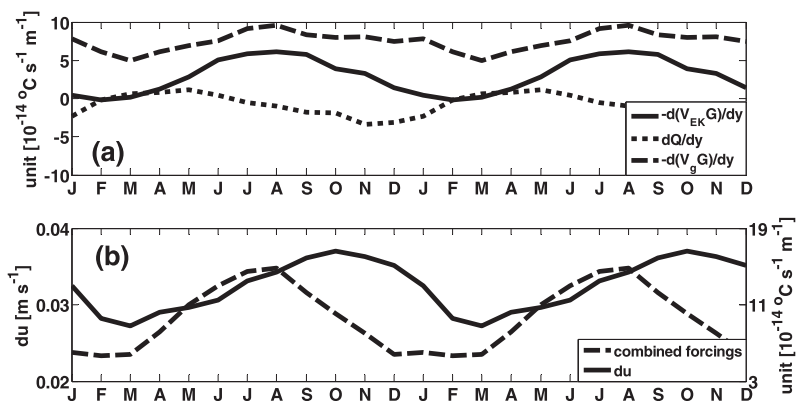

FIG. 10. (a) Meridional Ekman forcing term (solid line), geostrophic forcing term (dashed line), and heat flux forcing term (dotted line) in the southeast Indian Ocean $\left(15^{\circ}-30^{\circ} \mathrm{S}, 60^{\circ}-110^{\circ} \mathrm{E}\right)$ and (b) sum of the three forcing terms (dashed line) plotted with vertical shear, du (solid line).

\section{Summary and discussion}

Mesoscale eddy activity in the southeast Indian Ocean in the $20^{\circ}-30^{\circ} \mathrm{S}$ band is investigated using the $15-\mathrm{yr}$ satellite altimetry data. The observed sea level anomaly data shows that this region is the only eastern subtropical basin among the global oceans where enhanced mesoscale eddy variability exists. The eddy kinetic energy (EKE) in this region displays a distinct seasonal cycle with a maximum in summer and a minimum in winter. It is found that this seasonal modulation of EKE is mediated by baroclinic instability associated with the surface eastward-flowing SICC and the underlying westwardflowing SEC system. In austral spring, the enhanced flux forcing of combined meridional Ekman and geostrophic convergence strengthens the upper-ocean meridional temperature gradient, subsequently intensifying the SICC front and thus the vertical velocity shear. The modulation in the vertical velocity shear changes the intensity of baroclinic instability, leading to the observed seasonal variations of EKE in this region.

The $2 \frac{1}{2}-$-layer quasigeostrophic potential vorticity dynamics adopted in this study filtered out smaller length scale unstable modes identified in the continuously stratified models utilized by Smith (2007) and Killworth and Blundell (2007). It is important to note that the baroclinic instability involving the SICC and SEC shear identified in our present study within the quasigeostrophic dynamics (with the wavelengths of the most unstable waves at $\sim 200 \mathrm{~km}$ ) explains favorably the observed mesoscale eddy scales in the southeast Indian Ocean (cf. Fig. 8 versus 9). Here the mean background flow is fixed. It may also be useful to extend the theories of baroclinic instability to include a slowly varying mean flow. This will be investigated in the future.

Throughout this study, we have focused on the local mechanism associated with the baroclinic instability of the mean SICC-SEC current system. Mesoscale eddy activity in the southeastern Indian Ocean can also be affected by several other nonlocal processes, including the eastern boundary current, namely the Leeuwin Current (LC) variability, as well as the impacts from the tropical ocean via the Indonesian Throughflow. Previous studies indicated that the LC variability also has a well-defined seasonal cycle (Feng et al. 2003; Deng et al. 2008; Morrow and Birol 1998; Peter et al. 2005). Eddies and baroclinic Rossby waves are found to be generated by the LC variations and then propagate to the west (Schouten et al. 2002; Rennie et al. 2007; Morrow et al. 2003; Birol and Morrow 2001, 2003). A unique feature for the south Indian Ocean eastern basin boundary is the presence of the Indonesian Throughflow. Generation mechanisms for the mean SICC in the eastern basin of the subtropical south Indian Ocean are not well understood. Future studies are needed to quantify the importance of these eastern boundary processes in modulating the EKE level in the southeast Indian Ocean relative to that due to the baroclinic instability of the SICC-SEC system and to clarify the dynamics responsible for the formation of the mean SICC.

Acknowledgments. This work is supported by China National Natural Science Foundation Projects (40788002 and 40876001), the NSFC Creative Research Group Project (40921004), and the China Foreign Expert "111" project through the Ministry of Education. We appreciate comments from two anonymous reviewers and the editor Dr. Lynne Talley that improved the paper substantially. The altimeter products were produced by Ssalto/Ducas and distributed by AVISO with support from CNES.

\section{REFERENCES}

Antonov, J. I., and Coauthors, 2010: Salinity. Vol. 2, World Ocean Atlas 2009, NOAA Atlas NESDIS 69, 184 pp.

Biondi, F., A. Gershunov, and D. R. Cayan, 2001: North Pacific decadal climate variability since 1661. J. Climate, 14, 5-10.

Birol, F., and R. Morrow, 2001: Source of the baroclinic waves in the southeast Indian Ocean. J. Geophys. Res., 106, 9145-9160.

— and - 2003: Separation of the quasi-semiannual Rossby waves from the eastern boundary of the Indian Ocean. J. Mar. Res., 61, 707-723.

Deng, X., C. Hwang, R. Coleman, and W. E. Featherstone, 2008: Seasonal and interannual variations of the Leeuwin Current off Western Australia from TOPEX/Poseidon satellite altimetry. Terr. Atmos. Oceanic Sci., 19 (1-2), 135-149.

DeWeaver, E., and S. Nigam, 2000: Zonal-eddy dynamics of the North Atlantic Oscillation. J. Climate, 13, 3893-3914.

Ebuchi, N., and K. Hanawa, 2000: Mesoscale eddies observed by TOLEX-ADCP and TOPEX/Poseidon altimeter in the Kuroshio recirculation region south of Japan. J. Oceanogr., 56, $43-57$.

Feng, M., and S. Wijffels, 2002: Intraseasonal variability of the South Equatorial Current of the East Indian Ocean. J. Phys. Oceanogr., 32, 265-277. 
_, G. Meyers, A. Pearce, and S. Wijffels, 2003: Annual and interannual variations of the Leeuwin Current at $32^{\circ} \mathrm{S}$. J. Geophys. Res., 108, 3355, doi:10.1029/2002JC001763.

Halliwell, G. R., G. Peng, and D. B. Olson, 1994: Stability of the Sargasso Sea subtropical frontal zone. J. Phys. Oceanogr., 24, 1166-1183.

Imawaki, S., and Coauthors, 2001: Satellite altimeter monitoring the Kuroshio transport south of Japan. Geophys. Res. Lett., 28, 17-20.

Kalnay, E., and Coauthors, 1996: The NCEP/NCAR 40-Year Reanalysis Project. Bull. Amer. Meteor. Soc., 77, 437-471.

Killworth, P. D., and J. R. Blundell, 2007: Planetary wave response to surface forcing and instability in the presence of mean flow and topography. J. Phys. Oceanogr., 37, 1297-1320.

Kobashi, F., and H. Kawamura, 2002: Seasonal variation and instability nature of the North Pacific Subtropical Countercurrent and the Hawaiian Lee Countercurrent. J. Geophys. Res., 107, 3185, doi:10.1029/2001JC001225.

Ladd, C., 2007: Interannual variability of the Gulf of Alaska eddy field. Geophys. Res. Lett., 34, L11605, doi:10.1029/2007GL029478.

Locarnini, R. A., A. V. Mishonov, J. I. Antonov, T. P. Boyer, H. E. Garcia, O. K. Baranova, M. M. Zweng, and D. R. Johnson, 2010: Temperature. Vol. 1, World Ocean Atlas 2009, NOAA Atlas NESDIS 68, 184 pp.

Miller, A. J., and N. Schneider, 2000: Interdecadal climate regime dynamics in the North Pacific Ocean: Theories, observations and ecosystem impacts. Prog. Oceanogr., 47, 355-379.

Morrow, R., and F. Birol, 1998: Variability in the southeast Indian Ocean from altimetry: Forcing mechanisms for the Leeuwin Current. J. Geophys. Res., 103, 18 529-18 544.

— , F. Fang, M. Fieux, and R. Molcard, 2003: Anatomy of three warm-core Leeuwin Current eddies. Deep-Sea Res., 50, 2229-2243.

Palastanga, V., P. J. van Leeuwen, M. W. Schouten, and W. P. M. de Ruijter, 2007: Flow structure and variability in the subtropical Indian Ocean: Instability of the South Indian Ocean Countercurrent. J. Geophys. Res., 112, C01001, doi:10.1029/2005JC003395.

Penduff, T., B. Barnier, W. K. Dewar, and J. J. O'Brien, 2004: Dynamical response of the oceanic eddy field to the North Atlantic Oscillation: A model-data comparison. J. Phys. Oceanogr., 34, 2615-2629.
Peter, B. N., P. Sreeraj, and K. G. VimalKumar, 2005: Structure and variability of the Leeuwin Current in the south eastern Indian Ocean. J. Indian Geophys. Union, 9, 107-119.

Phillips, H. E., and S. R. Rintoul, 2000: Eddy variability and energetics from direct current measurements in the Antarctic Circumpolar Current south of Australia. J. Phys. Oceanogr., 30, 3050-3076.

Qiu, B., 1999: Seasonal eddy field modulation of the North Pacific Subtropical Countercurrent: TOPEX/Poseidon observations and theory. J. Phys. Oceanogr., 29, 2471-2486.

, 2002: The Kuroshio Extension system: Its large-scale variability and role in the midlatitude ocean-atmosphere interaction. J. Oceanogr., 58, 57-75.

— , and S. Chen, 2004: Seasonal modulations in the eddy field of the South Pacific Ocean. J. Phys. Oceanogr., 34, 1515-1527.

- , and 2010: Interannual variability of the North Pacific Subtropical Countercurrent and its associated mesoscale eddy field. J. Phys. Oceanogr., 40, 213-225.

Rennie, S. J., C. B. Pattiaratchi, and R. D. McCauley, 2007: Eddy formation through the interaction between the Leeuwin Current, Leeuwin Undercurrent and topography. Deep-Sea Res. II, 54, 818-836, doi:10.1016/j.dsr2.2007.02.005.

Schouten, M. W., W. P. M. de Ruijter, and P. J. van Leeuwen, 2002: Upstream control of the Agulhas ring shedding. J. Geophys. Res., 107, 3109, doi:10.1029/2001JC000804.

Screen, J., N. Gillett, D. Stevens, G. Marshall, and H. Roscoe, 2009: The role of eddies in the Southern Ocean temperature response to the southern annular mode. J. Climate, 22, 806-818.

Sen Gupta, A., and M. H. England, 2007: Coupled ocean-atmosphere feedback in the southern annular mode. J. Climate, 20, 3677-3692.

Siedler, G., M. Rouault, and J. R. E. Lutjeharms, 2006: Structure and origin of the subtropical South Indian Ocean Countercurrent. Geophys. Res. Lett., 33, L24609, doi:10.1029/2006GL027399.

Smith, K. S., 2007: The geography of linear baroclinic instability in Earth's oceans. J. Mar. Res., 65, 655-683.

Zhou, L., R. Murtugudde, and M. Jochum, 2008: Dynamics of the intraseasonal oscillations in the Indian Ocean South Equatorial Current. J. Phys. Oceanogr., 38, 121-132. 